\title{
고등학교 야구 선수의 투구 속도에 따른 운동학적 요소 분석
}

\author{
전정우, 유재호* \\ 선문대학교 물리치료학과
}

\author{
Analysis of kinematic difference according to velocity of ball in high school baseball player \\ Jeong-Woo Jeon, Jae-Ho Yu ${ }^{*}$ \\ Department of Physical Therapy, Sunmoon University
}

Purpose The purpose of this study is to investigate the difference of body kinematics according to velocity of ball in high school baseball players. Methods Ten high school baseball players participated in this study. They chose the ball speed themselves and threw the ball 10 times. Kinematic factors measured using the wearable Micro Electro-Mechanical Systems sensor (MVN, Xsens technologies B.V., Enschede, the Netherlands) include the range of motion of the shoulder, torso rotation angular velocity and stride length. One hundred pitching data were divided into fifty high velocity pitching (The average of velocity of ball is $113.52 \mathrm{~km} / \mathrm{h}$.) and fifty low velocity pitching (The average of velocity of ball is 94.82 $\mathrm{km} / \mathrm{h}$.). Kinematic factors of both pitching were analyzed by paired t-test. Significance level of all statistics were set as $\mathrm{p}<.05$. Results As shown in the results of measuring the range of motion of shoulder (external rotation and abduction), there were significant difference between the high velocity pitching and the low velocity pitching. Likewise, the results of torso rotation angular velocity showed a significant difference between the two pitching data and the stride length also showed a significant difference between the high and low pitching data. Conclusion In conclusion, range of motion of shoulder, torso rotation angular velocity and stride length are related to the velocity of the ball in baseball and should be considered for the ability of the pitcher.

Key words Baseball, Pitchers, Motion analysis, Kinematics, Inertial sensor

Corresponding author Jae Ho Yu (naresa@sunmoon.ac.kr)

$\begin{array}{ll}\text { Received date } & 9 \text { May } 2017 \\ \text { Revised date } & 2 \text { June } 2017 \\ \text { Accepted date } & 11 \text { October } 2017\end{array}$

This paper was supported by Ministry of Culture, Sports and Tourism (MCST) funded by Korea Sports Promotion Foundation.

\section{I. 서 론}

빠른 공을 던질 수 있는 능력은 야구 투수들의 성공을 위한 중 요한 요소 중 하나이다. 또한 조정희 등의 연구에서도 투수 훈 련의 목적 중 하나는 구속을 증가시키는 것이라고 보고하였 다. ${ }^{1)}$ 이에 따라 와인드업(wind-up), 스트라이드(stride), 코킹 (arm cocking), 가속구간(arm acceleration), 감속구간(arm deceleration), 팔로우(follow through)로 이어지는 투구 단 계 동안에 구속에 영향을 미치는 요인들을 파악하기 위한 인체 의 운동학적 및 운동역학적 분석 연구들을 지속적으로 진행하 고 있다. ${ }^{2,3,4)}$

doi : http:dx.doi.org/10.17817/2017.06.12.111159
Matsuo 등의 연구에서 구속이 빠른 집단과 느린 집단을 비교하여 신장, 팔 길이, 생체역학 요인들(오픈 팔로 투구 시 디딤 축이 되는 왼쪽 무릎의 굽힘 각속도(lead knee flexion angular velocity), 코킹 시의 어깨관절의 최대 가쪽돌림 각 도, 볼 릴리즈(ball release) 시기의 왼쪽 무릎의 폄 각속도 (lead knee extension angular velocity) 등)에서 유의한 차이를 보였다고 보고하였다. ${ }^{5)}$ Stodden 등의 연구에서는 어 깨관절의 벌림 및 수평벌림 각도, 안쪽돌림의 각속도, 볼 릴리 즈 시기의 몸통 앞쪽 경사(trunk tilt forward)가 구속에 영향 을 미친다고 보고하였다. ${ }^{6}$ 또 다른 연구에서도 마찬가지로 구 속에 영향을 미치는 요인들로 SFC(stride foot contact)시의 무릎관절과 팔꿉관절 굽힘 각도, 어깨관절 최대 각속도, 어깨관 절의 최대 가쪽돌림 각도, 팔꿉관절의 최대 폄 각속도, 볼 릴리 
즈 시의 무릎관절 굽힘각도와 몸통 앞쪽 경사가 있다고 보고하 였다. ${ }^{2)}$ 이러한 연구들의 결과는 감독들과 코치 그리고 선수들 에게 구속을 증가시키기 위해 영향을 미치는 요인들에 대한 정 보를 제공하고 실제 훈련에서도 적용할 수 있다.

지금까지 진행되어 온 야구 투수의 투구동작에 대한 운동 학적 연구들을 살펴보면, 대부분 카메라 촬영을 기반으로 한 3 차원 동작분석 시스템(3D motion capture system)을 사용 하였다. ${ }^{6,78)}$ 실제로 다양한 분야에서 이러한 운동학적 연구들 이 진행되고 있지만 이 방법에서 몇몇 제한점들이 보고되고 있 다. 첫째로 연구실의 환경, 마커(maker)의 부착위치, 캘리브레 이션(calibration) 등의 변수들이 결과 값의 오차를 발생시킬 수 있다. 다음으로 실제 야구는 야외에서 진행되는 경기이지만 3 차원 동작분석 시스템을 사용할 경우 연구 환경에 대한 제약 을 받아 실내에서 연구가 이루어지는 경우가 많다. 또한 연구 자들은 카메라의 캡쳐(capture) 범위를 고려해 연구를 진행해 야 한다.

3 차원 동작분석 시스템의 제한점을 보고한 몇몇 연구자들은 관성 및 자기 센서(inertial and magnetic sensors)를 활용해 실제 일상생활이 이뤄지는 환경에서의 연구를 실시하였다., ${ }^{910)}$ 이 센서는 신체의 서로 다른 분절에 부착되어 선형 가속도, 각 속도 및 자기장 세기를 측정하여 정보를 제공한다. 위의 센서와 마찬가지로 관성 센서 기반 운동 분석 시스템인 Xsens MVN BIOMECH system(Xsens Technologies BV, Enschede, Netherlands)은 특정 생체역학 모델과 알고리즘을 사용하여 관절의 운동학적 요소를 추정하여 정보를 제공한다. ${ }^{11)}$

따라서 본 연구의 목적은 기존 투구동작 분석을 위해 사용 되어 온 카메라 촬영 기반 한 3 차원 동작분석 시스템이 아닌 관성 센서 기반 운동 분석 시스템을 활용하여 고등학교 야구 선수들의 투구 속도에 따른 운동학적 요소들을 분석하고 야구 선수들과 코치 그리고 부상 후 재활을 담당하는 치료사들에게 구속과 관련된 운동학적 정보를 제공하는 데에 있다.

\section{II. 연구 방법}

\section{1. 연구대상자}

본 연구에는 연구에 대해 충분히 이해하고 동의한 고등학교 야 구선수 투수 10 명의 대상자가 참여하였다. 대상자들은 모두 오 른손잡이였고 오버 핸드 투수들이었다. 대상자의 제외기준은 다음과 같다. 1) 최근 6 개월 내에 하지 혹은 상지의 외과적 수 술을 받은 경험이 있는 자, 2) 심각한 통증 혹은 부상으로 인 해 현재 치료 중이거나 재활 훈련 중인 자, 3) 다른 이유들로 인해 공을 던지는 데 어려움이 있는 자. 사이드 암(side-arm; submarine) 투수들은 오버핸드 투수들과 다른 투구 메커니즘

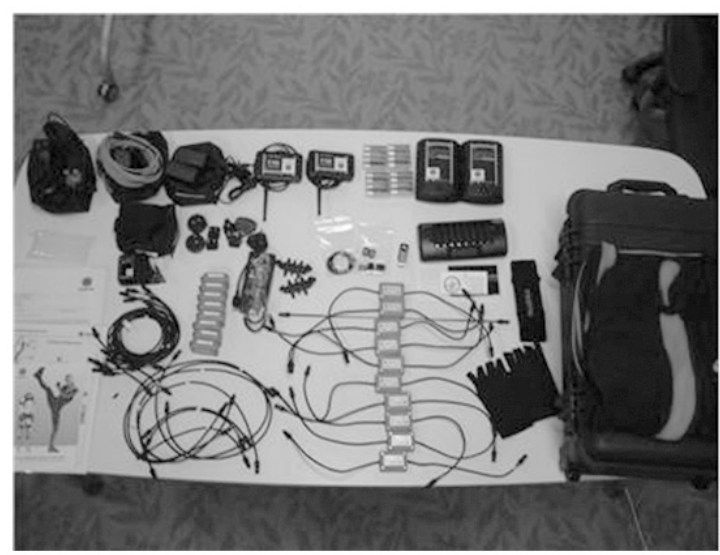

Figure 1 Xsens MVN BIOMECH system(Xsens Technologies BV, Enschede, Netherlands)

을 갖기 때문에 본 연구에서 제외되었다.

\section{2. 실험 절차}

모든 대상자들은 상지와 하지의 스트레칭 및 투구 동작 연습을 포함한 준비운동을 15 분 동안 실시한 후에 운동학적 요소를 분석하기 위해 Xsens 슈트 착용 및 센서를 부착하였다(figure 1). 그 이후 빠른 속도와 느린 속도로 각각 5 개씩 공을 던지도 록 요구 받았다. 공을 한 번 던지고 다음 공을 던질 때까지 30 초의 휴식을 취했다. 위 과정의 결과로 빠른 속도로 공을 던질 때의 투구 동작 데이터 50 개(high velocity pitching), 느린 속도로 공을 던질 때의 투구 동작 데이터 50 개(low velocity pitching)가 수집되었다. 대상자들이 공을 던지는 동안 운동학 적 요소들은 착용이 가능한 관성 센서 기반 운동 분석 시스템 Xsens MVN BIOMECH system(Xsens Technologies BV, Enschede, Netherlands)을 이용해 수집되었다. 측정된 운동 학적 요소들은 다음과 같다. 1) 어깨관절의 수평벌림 각도. 2) 어개관절의 가쪽돌림 각도 3) 몸통 회전 각속도(trunk rotation angular velocity). 4) 스트라이드 거리(stride length). 어깨 관절의 수평 벌림 각도와 가쪽돌림 각도는 $\mathrm{SFC}$ 시의 최대로 일 어난 각도를 측정하였다. 몸통의 회전 각속도는 와인드업 구간 에서 몸이 뒤쪽으로 최대 회전한 각도에서부터 볼 릴리즈 구간 에서 몸이 앞쪽으로 최대 회전한 각도 범위까지의 각속도를 구 하였다. 스트라이드 거리는 대상자의 앞쪽 발(왼발)이 지면에 닿는 순간, 뒤쪽 발의(오른발) 엄지발가락과 앞쪽 발의 뒤꿈치 사이의 거리를 측정하였다. 측정된 스트라이드 거리 값은 대상 자들의 신장에 대한 비율 $(\% \mathrm{H})$ 로 나타내었다.

\section{3. 통계분석}

모든 측정값은 평균과 표준편차를 구하였다. 대상자의 구속에 따른 (high velocity pitching, low velocity pitching) 운동 


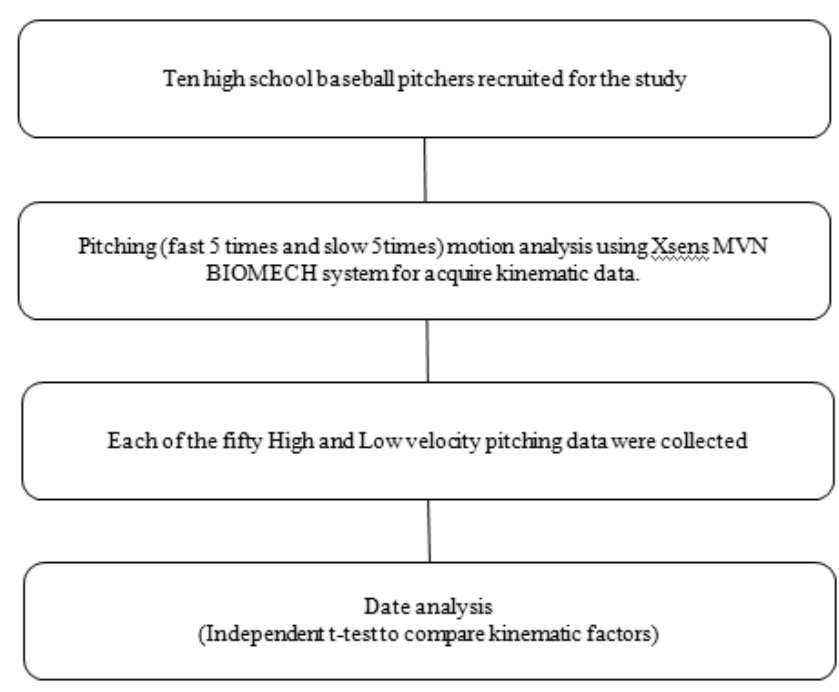

Figure 2 procedure flow chart

Table 1. General characteristics of the subjects $(n=10)$

\begin{tabular}{cc} 
& Pitchers \\
Age (years) & $18.43 \pm 0.45$ \\
Height $(\mathrm{cm})$ & $181.97 \pm 2.79$ \\
Weight $(\mathrm{kg})$ & $83.44 \pm 7.12$ \\
\hline
\end{tabular}

Mean \pm Standard deviation

학적 요소 차이를 알아보기 위해 SPSS statistical software (version 22.0; IBM Corp, Armonk, NY)를 이용하여 대응 표본 t-검정(paired t-test)를 실시하였다. 모든 통계학적 유의 수준은 $\mathrm{p}<.05$ 로 설정하였다.

\section{III. 결 과}

본 연구에 참여한 고등학교 야구 투수들은 총 10 명(남자 10명) 이며, 평균연령은 18.43 세, 평균신장은 $181.97 \mathrm{~cm}$ 평균체중은
$83.44 \mathrm{~kg}$ 이었다(Table 1).

공을 빠르게 던졌을 때(high velocity)와 느리게 던졌을 때(low velocity)의 구속은 각각 $113.52 \pm 6.59,94.82 .7 .12$ 였 다. 어깨관절 수평벌림 각도는 각각 $102.43 \pm 15.09$, $94.74 \pm 10.32$ 로 빠르게 던졌을 때 더 큰 각도를 보였으며 통계 적으로 유의한 차이를 나타내었다 $(\mathrm{p}<.05)$. 어깨관절의 가쪽돌 림 각도는 각각 $107.23 \pm 14.37,93.91 \pm 34.91$ 로 빠르게 던졌을 때 더 큰 각도를 보였으며 통계적으로 유의한 차이를 나타내었 다(p<.05). 몸통 회전 각속도는 각각 $907.13 \pm 109.66$,

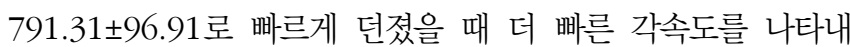
었고 통계적으로 유의한 차이를 나타냈다 $(\mathrm{p}<.05)$. 스트라이드 거리는 $80.12 \pm 5.13,75.72 \pm 5.73$ 으로 빠르게 던졌을 때 더 크 게 나타내었으며 통계적으로도 유의한 차이를 나타냈다 $(\mathrm{p}<.05)($ Table 2).

\section{IV. 고 찰}

본 연구는 관성 센서 기반 운동 분석 시스템을 활용하여 고등 학교 야구 투수 선수들을 대상으로 투구 속도에 따른 운동학적 요소의 차이를 알아보고자 하였다. 연구 결과에 따르면 투수가 공을 빠르게 던졌을 때 느리게 던졌을 때보다 어깨관절의 최대 운동범위(수평벌림, 가쪽돌림)의 각도가 더 크게 나타났으며 몸통의 회전 각속도도 더 빠르게 나타났다. 스타라이드 거리 또한 더 큰 거리를 나타냈다.

투수가 공을 빠르게 던졌을 때, 느리게 던졌을 때보다 어깨 관절의 수평벌림과 가쪽돌림의 최대 각도가 더 크게 나타난 본 연구 결과와 마찬가지로Escamilla 등의 연구에서도 같은 결과 를 보고했다. Escamilla 등은 미국과 한국의 프로야구 투수 선 수들을 대상으로 운동역학 및 운동학적 요소들의 비교 분석을 실시하였다. ${ }^{12)}$ 연구 결과에 따르면 미국 투수들의 구속이 한국 투수들의 구속보다 더 빠르게 측정되었고 왼쪽 발이 지면에 닿 는 시점(lead foot contact)에서 미국 투수들의 어깨관절의

Table 2. Kinematic differences according to velocity of ball

\begin{tabular}{|c|c|c|c|}
\hline & High velocity & Low velocity & $\mathrm{p}$ \\
\hline Velocity of ball $(\mathrm{km} / \mathrm{h})$ & $113.52 \pm \quad 6.59$ & $94.82 \pm 7.12$ & .00 \\
\hline Maximum shoulder horizontal abduction $\left(^{\circ}\right)$ & $14.27 \pm 10.80$ & $3.17 \pm 16.91$ & .00 \\
\hline Maximum shoulder external rotation $\left(^{\circ}\right)$ & $107.23 \pm 14.37$ & $93.91 \pm 34.91$ & .02 \\
\hline Torso rotation angular velocity $(\mathrm{o} / \mathrm{s})$ & $907.13 \pm 109.66$ & $791.31 \pm 96.91$ & .00 \\
\hline Stride length $(\mathrm{H} \%)$ & $80.12 \pm \quad 5.13$ & $75.72 \pm 5.73$ & $.00^{*}$ \\
\hline
\end{tabular}

Mean \pm Standard deviation

$\mathrm{H} \%$ : height $\%$

* Significant difference $(p<.05)$ between high and low velocity pitching. 
수평벌림과 가쪽돌림 각도 범위가 더 크게 나타났다고 보고하 였다. 이러한 결과의 원인으로는 다음과 같이 설명했다. 코킹 단계에서 어깨관절 가쪽돌림이 일어나는 동안 안쪽돌림근의 원 심성 수축 및 스트레칭이 일어나게 되는데 이를 통해 가쪽돌림 의 속도를 조절할 수 있다. 이 과정에서 안쪽돌림근 내에 탄성 에너지(elastic energy)를 저장하게 된다. 이렇게 저장된 탄성 에너지와 스트레칭된 근육의 근신전반사(myotatic reflex) 효 과를 통해 가속 구간 동안 안쪽돌림근의 더 강한 구심성 수축 을 일으키게 된다. 강한 구심성 수축은 결과적으로 더 빠른 공 을 던질 수 있는 힘을 만들어 낸다. 수평벌림의 경우도 이와 같이 탄성에너지와 근신전반사의 영향을 받았을 것으로 판단된 다. 또한 수평벌림이 일어나는 동안에는 어깨관절 근육들뿐 아 니라 몸통 근육의 원심성 수축과 스트레칭이 함께 일어나게 되 므로 몸통과 골반의 회전 각속도를 증가시키는 힘으로 작용하 게 된다. ${ }^{2)}$ 본 연구에서도 공을 빠르게 던졌을 때 더 큰 어깨 관절의 범위가 측정된 이유가 근육 내에 저장되는 탄성에너지 와 근신전반사의 이유라고 생각된다.

공을 빠르게 던질 때 더 빠른 몸통의 회전 각속도가 측정 되었다. Aguinaldo등은 선행 연구결과에 따라 야구 투구 동작 이 다른 오버핸드 스포츠처럼 힘과 속도를 만들어내기 위해 더 큰 신체 부위에서 작은 원위 분절로의 이동하는 운동량이 필요 하다고 하였다. ${ }^{13)}$ 즉 야구 동작에서 몸통에서 상지로의 에너지 전달은 공을 더 빠르게 던지기 위한 요소 중 하나로 생각되고 이 에너지 전달은 더 빠른 몸통 회전으로 일어날 수 있다. 또 한 몸통의 회전 각속도가 증가함에 따라 공을 던지는 상지로의 에너지 전달이 증가하게 된다고 보고하였다. ${ }^{14)}$

스트라이드 거리는 운동역학 사슬의 타이밍을 결정하는 중 요한 요소로 간주될 뿐 아니라 하지에서 공을 던지는 팔로 에 너지를 전환시키는 역할을 한다. 즉 몸통에서 발생하는 에너지 를 회전을 통해 공을 던지는 팔로 전달하는 것과 같이 더 넓은 스트라이드 거리는 효율적으로 공을 던지는 팔로 하지의 에너 지를 전달해준다고 할 수 있다. Terrance 등 또한 스트라이드 거리가 대상자 신장의 $10 \%$ 증가할 때, $1.9 \pm 0.4 \mathrm{mph}$ 의 속도 가 증가된다고 보고하였다. ${ }^{15)}$ 결과적으로 투수 코치는 투수의 구속을 높이기 위해 스트라이드 거리에 초점을 맞추어야 한다.

다만 야구 투구 동작의 경우 어깨관절의 작용이나 몸통 회 전 각속도의 작용 등 한 가지 동작으로 인해 일어나는 것이 아 닌 몸 전체를 사용하는 연속적인 동작이므로 공의 속도와 생체 역학적 요소의 비교만으로 설명될 수는 없을 것이다. 예를 들 어 공을 빠르게 던졌을 때의 몸통 회전 각속도와 어깨관절의 운동범위의 상관관계와 같은 연구를 통해 생체역학적 요소들 간에 일어나는 상호적인 영향을 알아보고 이에 대한 이해가 함 께 필요할 것으로 판단된다.

야구를 비롯한 스포츠 분야뿐 아니라 다양한 분야에서 카
메라 촬영을 기반으로 한 3 차원 동작분석 시스템이 활발하게 사용되고 있음에도 불구하고 이 방법에 대한 제한점이 지속적 으로 보고되고 있다. 고가의 장비이며 카메라가 설치되어 있는 공간에서만 사용 될 수 있고 위치와 속도, 가속도를 포함하는 운동학적 요소들은 포함되지만 운동역학적 정보들은 알 수 없 다. 또한 실험 준비와 캘리브레이션, 마커부착 등에 많은 시간 이 소요된다. 이러한 제한점들로 인해 최근 몇몇 연구자들은 관성 센서 기반 운동 분석 시스템을 사용하여 생체역학 정보를 측정하였다. 본 연구에서도 관성 센서 기반 운동 분석 시스템 을 사용하여 운동학적 요소들을 측정하였는데, 카메라 촬영 기 반 동작분석 시스템 연구들의 결과와 마찬가지로 공의 속도에 따라 운동학적 요소들 간의 유의한 차이가 나타났지만 두 시스 템의 실제 결과 값 에는 차이가 있었다.

Jun-Tian Zhang 등은 또 다른 동작분석 시스템인 NDI Optotrak 3020 system(Northern Digital Inc., Ontario, Canada)과 본 연구에서 사용한 Xsens MVN BIOMECH system(Xsens Technologies BV, Enschede, Netherlands) 을 동시에 사용하여 관성 센서 기반 운동 분석 시스템의 신뢰 성을 검증하는 연구를 실시하였다. ${ }^{11)}$ 연구 결과에 따르면 굽힘 과 폄은 0.96 이상의 높은 상관계수를 나타냈지만 다른 회전축 에 의한 움직임은 0.5 0.85로 현저하게 낮게 측정되었다. 이러 한 결과는 두 시스템에서의 해부학적 축이 다르게 설정되었기 때문에 나타났다고 보고하였다. 따라서 Xsens MVN $\mathrm{BIOMECH}$ system을 사용하여 생체역학 정보를 측정할 경우 Optotrak뿐 아니라 기존 카메라 기반 시스템을 통해 측정된 결과 값을 보완하여 수치를 처리하는 절차가 필요하다. ${ }^{11)}$

본 연구의 제한점으로는 첫째, 대상자의 수가 10 명으로 일 반화하기에는 대상자의 수가 부족했다. 둘째로 본 연구의 대상 자들은 고등학교 야구 선수들이기 때문에 프로야구 선수들의 생체역학 정보와는 차이가 있을 수 있다. 셋째로 본 연구는 운 동학적 요소들의 비교만 이루어졌고 운동역학적인 요소들은 고 려되지 않았다. 마지막으로 공을 빠르게 던질 때와 느리게 던 질 때 운동학적 요소의 유의한 차이가 나타났지만 실제 결과 값은 기존 카메라 기반 동작분석 시스템을 활용한 연구들과의 차이가 있었다.

결론적으로 고등학교 야구 선수의 투구 속도에 따른 운동 학적 요소 차이는 기존 카메라 기반 시스템을 통한 결과와 같 이 관성 센서 기반 시스템을 통해서도 빠르게 던질 때와 느리 게 던질 때 어깨관절의 최대 범위, 몸통 회전 각속도, 스트라이 드 거리에서 유의한 차이를 나타냈다. 따라서 투수의 구속을 증가시키고자 할 때 위와 같은 운동학적 요소들이 고려되어야 한다. 그러나 본 연구에서 사용된 관성 센서 기반 동작 분석 시스템은 기존의 카메라 촬영 기반 동작 분석 시스템과 비교했 을 때, 실제 결과 값에 대한 차이가 존재하기 때문에 관성 센 
서 기반 동작분석 시스템을 활용한 추후 연구들이 더 활발하게 진행되기 위해서는 기존 동작분석 시스템 결과 값과의 차이를 분석하고 보완하는 과정이 우선적으로 이루어져야 할 것이다.

\section{References}

1. Cho JH, Lim SK, Kwon TY, et al. The correlation between throwing speed and shoulder internal/external rotator, trunk flexor/extensor, knee flexor/extensor strength and power in the professional baseball pitchers. J Kor Sports Med. 2006;24(2):158-63.

2. Werner SL, Suri M, Guido JA Jr, et al. Relationships between ball velocity and throwing mechanics in collegiate baseball pitchers. J Shoulder Elbow Surg. 2008;17(6):905-8.

3. Werner SL, Guido JA, Delude NA, et al. Throwing arm dominance in collegiate baseball pitching. Am J Sports Med. 2010;38(8):1606-10.

4. Dun S, Fleisig GS, Loftice J, et al. The relationship between age and baseball pitching kinematics in professional baseball pitchers. J Biomech. 2007;40(2): 265-70.

5. Matsuo T, Escamilla RF, Fleisig GS, et al. Comparison of kinematic and temporal parameters between different pitch velocity groups. J Appl Biomech. 2001;17(1):1-13.

6. Stodden DF, Fleisig GS, McLean SP, et al. Relationship of biomechanical factors to baseball pitching velocity: within pitcher variation. J Appl Biomech. 2005;21(1):44-56.

7. Fleisig GS, Laughlin WA, Aune KT, et al. Differences among fastball, curveball, and change up pitching biomechanics across various levels of baseball. Sports Biomech. 2016;15(2): 128-38.

8. Oyama S. Baseball pitching kinematics, joint loads, and injury prevention. Journal of Sports and Health. 2012;1(2):80-91.

9. Menguc Y, Park YL, Pei H, et al. Wearable soft sensing suit for human gait measurement. Int $\mathrm{J}$ Rob Res. 2014;33(14):1748-64.

10. Latella C, Kuppswamy N, Romano F, et al. Whole-body human inverse dynamic with distributed Micro-Accelerometer Gyro and Force Sensing. Sensors. 2016;16(5):727.

11. Zhang JT, Novak AC, Brouwer B, et al. Concurrent validation of Xsens MVN measurement of lower limb joint angular kinematics. Physiol meas. 2013;34(8):63-9.

12. Escamilla R, Flesig G, Barrentine S, et al. Kinematic and kinetic comparison between American and Korean professional baseball pitchers. Sports Biomech. 2002;1(2):213-28.

13. Aguinaldo AL, Buttermore J, Chambers H. Effects of upper trunk rotation on shoulder joint torque among baseball pitchers of various levels. J Appl Biomech. 2007;23(1):42-51

14. Stodden DF, Langendorfer SJ, Fleisig GS, et al. Kinematic constraints associated with the acquisition of overarm throwing part 1: step and trunk actions. Res Q Exerc Sport. 2006;77(4):417-27.

15. Sgroi T, Chalmers PN, Riff AJ, et al. Predictors of throwing velocity in youth and adolescent pitchers. J Shoulder Elbow Surg. 2015;24(9):1339-45. 
